\title{
A new anthracycline from endophytic Streptomyces sp. YIM66403
}

\author{
Wei $\mathrm{Li}^{1,3}$, Xueqiong Yang ${ }^{1,3}$, Yabin Yang ${ }^{1}$, Lixing $\mathrm{Zhao}^{2}$, Lihua $\mathrm{Xu}^{2}$ and Zhongtao Ding ${ }^{1}$ \\ The Journal of Antibiotics (2015) 68, 216-219; doi:10.1038/ja.2014.128; published online 24 September 2014
}

Species of Streptomyces are well known producers of diverse biological metabolites, and anthracyclines are one class of the typical antitumor antibiotics in drug studies. As one of the longest known antibiotics, anthracyclines have been received great attention frequently since its first discovery. ${ }^{1}$ Some of these anthracyclines have been used in medicine for the treatment of some cancers. ${ }^{2,3}$ Moreover, even in recent years, novel anthracyclines are constantly being discovered, such as aranciamycin anhydride. ${ }^{4}$ In our effort to search for new biological compounds from endophytes, a Streptomyces sp. YIM66403 producing special orange pigments caught our attention. Large-scale fermentation and subsequent fractionation of the extract of broth and mycelium proved that Streptomyces sp. YIM66403 was a strain yielding anthracyclines. As a result, we isolated a new anthracycline misamycin (1), together with $\eta$-pyrromycinone (2), 4-Deoxy- $\varepsilon$-pyrromycinone $(3)^{6}$ and other six known anthracyclines including cinerubin A (4), ${ }^{7}$ cinerubin $\mathrm{B}(5),{ }^{7}$ antibiotic $80334 \mathrm{C}$ (6) ${ }^{8}$ cinerubin X (7) ${ }^{9}$ collinemycin $(8)^{10}$ and musettamycin $(9)^{10}$ (Figure 1). Compound $\mathbf{1}$ showed cytotoxicity in the 3-(4,5-dimethylthiazol-2-yl)-5(3-carboxymethoxyphenyl)-2-(4-sulfopheny)-2H-tetrazolium (MTS) method and anti-Staphylococcus aureus activity in comparison with other antimicrobial activity.

The structure of misamycin (1) was established by various spectroscopic methods, whereas the structures of other known compounds (2-9) were confirmed by comparing their ${ }^{1} \mathrm{H}$ and ${ }^{13} \mathrm{C}-\mathrm{NMR}$ data with these of compounds in the literature. In this paper, we would like to report the isolation, structure determination and biological activity of $\mathbf{1}$.

The strain YIM66403 was isolated using glycerol-asparagine medium ( $1 \%$ glycerol, $0.1 \%$ asparagine, $0.1 \%$ dipotassium hydrogen phosphate, $1.2 \%$ agar, $\mathrm{pH}$ 7.2) from a healthy stem of the traditional Chinese medicinal plant Isodon eriocalyx obtained from Xishuangbanna, Yunnan, China, and was identified as Streptomyces sp. by $16 \mathrm{~S}$ rRNA gene sequence. The seed medium consisted of $0.4 \%$ malt extract, $0.5 \%$ yeast extract, $0.5 \%$ glucose (adjusted to $\mathrm{pH} 7.2$ before sterilization). Strain YIM66403 was cultured in $500 \mathrm{ml}$ erlenmeyer flasks each containing $200 \mathrm{ml}$ seed culture. After 4 days of incubation at $28^{\circ} \mathrm{C}$ on a rotary shaker $(125 \mathrm{r} . \mathrm{p} . \mathrm{m}$.), $10 \mathrm{ml}$ portion of the culture was inoculated into $1000 \mathrm{ml}$ erlenmeyer flasks each containing $250 \mathrm{ml}$ of fermentation medium consisting of $0.5 \%$ yeast extract, $2.4 \%$ soluble starch, $0.1 \%$ glucose, $0.3 \%$ beef extract, $0.3 \%$ peptone, $0.4 \%$ calcium carbonate (adjusted to $\mathrm{pH} 7.0$ before sterilization). The fermentation was carried out at $28^{\circ} \mathrm{C}$ on a rotary shaker $(125$ r.p. m.) for 8 days. A total of 1001 of fermentation broth was collected, and the broth and mycelium were separated. The broth was extracted with ethyl acetate, and the combined extracts were concentrated under reduced pressure to give the crude residue $(23 \mathrm{~g})$. The mycelium was extracted with acetone for $30 \mathrm{~min}$. The solvent was removed under vacuum and the remaining water phase was extracted with ethyl acetate; after concentration, $500 \mathrm{~g}$ oily crude extract was obtained. A flow diagram for the extraction of anthracyclines is shown in Scheme 1.

Compound 1 was isolated as amorphous powder. A molecular ion peak $\mathrm{m} / \mathrm{z} 656.2480$ was observed based on the high-resolution MS analysis of 1 (calcd for $\mathrm{C}_{34} \mathrm{H}_{40} \mathrm{O}_{13}, 656.2469$ ), consistent with a molecular formula of $\mathrm{C}_{34} \mathrm{H}_{40} \mathrm{O}_{13}$. The ${ }^{1} \mathrm{H}-{ }^{1} \mathrm{H}$ COSY correlations from $\mathrm{H}-2$ to $\mathrm{H}-3, \mathrm{H}-7$ to $\mathrm{H}-8$ and $\mathrm{HMBC}$ correlations from $1-\mathrm{OH}$ to $\mathrm{C}-1 / 2 /$ 12a, H-2 to C-4, H-3 to C-1, $4-\mathrm{OH}$ to C-3/4/4a, $6-\mathrm{OH}$ to C-5a/6/6a, $\mathrm{H}-7$ to $\mathrm{C}-6 / 9, \mathrm{H}-8$ to $\mathrm{C}-10, \mathrm{H}-10$ to $\mathrm{C}-13, \mathrm{H}-11$ to $\mathrm{C}-10 / 12, \mathrm{H}-14$ to $\mathrm{C}-13$ drew the skeleton of anthracycline for us. Then the ${ }^{13} \mathrm{C}-\mathrm{NMR}$ data comparison with its analog musettamycin $(9)^{10}$ confirmed our conclusion. Compared the NMR data of compound 1 with that of musettamycin (9), it was found that $\mathrm{N}-\mathrm{CH}_{3}$ and two $\mathrm{CH}$ (bearing respectively amino-group and hydroxyl ) were missing in $\mathbf{1}$, but two $\mathrm{CH}_{2}$ were additional in structure of $\mathbf{1}$, although the structure of $\mathbf{1}$ was similar to that of musettamycin, the two $\mathrm{CH}$ were replaced by $\mathrm{CH}_{2}$ in the structure of $\mathbf{1}$. The correlations of COSY and HMBC in compound 1 were determined in this elucidation (Figure 2). The $\mathrm{C}-1^{\prime}$ of rhodinose connected to $\mathrm{C}-7$ was confirmed by the correlations from $\mathrm{H}-7$ to $\mathrm{C}-1^{\prime}$ in $\mathrm{HMBC}$. The COSY correlations from $\mathrm{H}-1^{\prime}$ to $\mathrm{H}-6^{\prime}$, and the HMBC correlations from $\mathrm{H}-6^{\prime}$ to $\mathrm{C}-4^{\prime}, \mathrm{H}-4^{\prime}$ to $\mathrm{C}-2^{\prime}$ confirmed that the oxygen atom was connected to $\mathrm{C}-4^{\prime}$, together with the COSY correlations from $\mathrm{H}-\mathrm{1}^{\prime \prime}$ to $\mathrm{H}-6^{\prime \prime}$, and the $\mathrm{HMBC}$ correlations from

${ }^{1}$ Key Laboratory of Medicinal Chemistry for Natural Resource, Ministry of Education, School of Chemical Science and Technology, Yunnan University, Kunming, China and

${ }^{2}$ Yunnan Institute of Microbiology, Yunnan University, Kunming, China

${ }^{3}$ These authors contributed equally to this work.

Correspondence: Professor Z Ding, Key Laboratory of Medicinal Chemistry for Natural Resource, Ministry of Education, School of Chemical Science and Technology, Yunnan University, Kunming 650091, China.

E-mail: ztding@ynu.edu.cn

Received 26 March 2014; revised 14 August 2014; accepted 22 August 2014; published online 24 September 2014 
<smiles>[R]O[C@H]1C[C@](O)(CCC)[C@@H]([2H])[C@H](C(C)=O)c2cc3c(c(O)c21)C(=O)c1c(O)ccc(O)c1C3=O</smiles><smiles></smiles>

$1 \mathrm{R}=\mathrm{R}_{1} \quad 5 \mathrm{R}=\mathrm{R}_{3} \quad 9 \mathrm{R}=\mathrm{R}_{5}$

$4 \mathrm{R}=\mathrm{R}_{2} \quad 7 \mathrm{R}=\mathrm{R}_{4}$<smiles>CCc1ccc2c(O)c3c(cc2c1C(=O)OC)C(=O)c1c(O)ccc(O)c1C3=O</smiles><smiles>CC[C@@]1(O)CCc2c(cc3c(c2O)C(=O)c2c(O)ccc(O)c2C3=O)[C@H]1C(=O)OC</smiles>

2

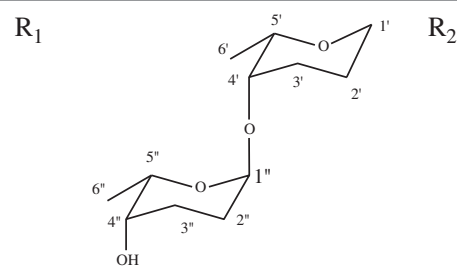

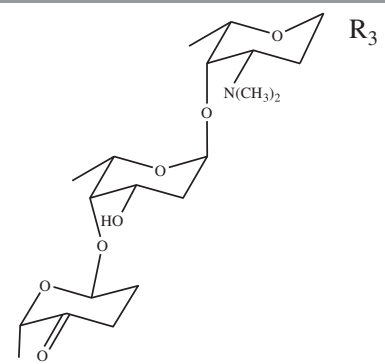

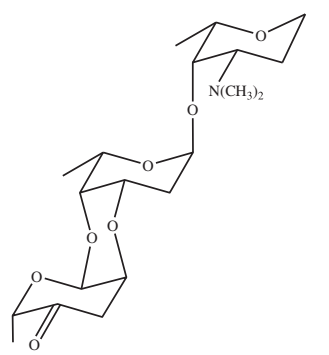

$\mathrm{R}_{4}$

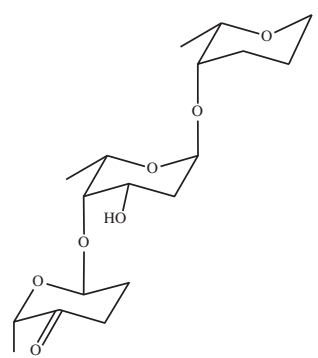

$\mathrm{R}_{5}$

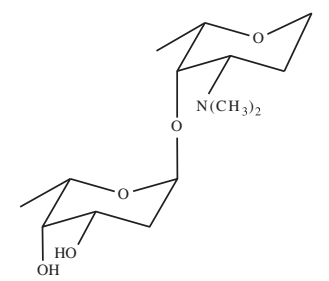

Figure 1 Structures of compounds 1-9.

$\mathrm{H}-6^{\prime \prime}$ to $\mathrm{C}-4^{\prime \prime}, \mathrm{H}-4^{\prime \prime}$ to $\mathrm{C}-3^{\prime \prime}$ confirmed that the another $\mathrm{OH}$ was connected to $\mathrm{C}-4^{\prime \prime}$. The $\mathrm{C}-1^{\prime \prime}$ of rhodinose connected to C-4' was confirmed by the correlation from $\mathrm{H}-1^{\prime \prime}$ to $\mathrm{C}-4^{\prime}$ in HMBC. By comparison with the NMR of known anthracyclines isolated from this strain, the configurations of compound 1 were determined having the same structure as musettamycin. The configurations of C-9,10 were determined as $\mathrm{R}$ by the chemical shift at C-16 ( $\delta$ 6.66) compared with the NMR data of antibiotic 80334 B. ${ }^{8}$ The structure of compound 1 was described in $\mathrm{PhD}$ thesis of Balk-Bindseil. ${ }^{11}$ The anomeric configurations of two sugars were determined to be all $\alpha$ by the coupling constants of the anomeric protons of rhodinoses, $\mathrm{H}-\mathrm{l}^{\prime}$ (d, $J=2.8 \mathrm{~Hz})$ and $\mathrm{H}^{\prime \prime} 1^{\prime \prime}(\mathrm{d}, J=3.4 \mathrm{~Hz})$. The relative configurations between $\mathrm{H}-4^{\prime}$ and $\mathrm{H}-5^{\prime}, \mathrm{H}-4^{\prime \prime}$ and $\mathrm{H}-5^{\prime \prime}, \mathrm{H}-\mathrm{1}^{\prime}$ and $\mathrm{H}-6^{\prime}, \mathrm{H}-\mathrm{I}^{\prime \prime}$ and H- $6^{\prime \prime}$ in the structures of sugars were also confirmed as cis-form by the NOESY correlations between them.

Misamycin (1): amorphous powder; $[\alpha]_{\mathrm{D}}^{25}+43.2($ c $0.8, \mathrm{MeOH})$; UV (MeOH) $\lambda_{\max }(\log \varepsilon)$ 491(3.32), 256 (4.74), 232 (4.16) nm; IR
$(\mathrm{KBr}) \nu_{\max } 3441,2931,2354,1732,1602,1449,1213,1004 \mathrm{~cm}^{-1} ;{ }^{1} \mathrm{H}$ $\operatorname{NMR}\left(400 \mathrm{MHz}, \mathrm{CDCl}_{3}\right)$ and ${ }^{13} \mathrm{C} \mathrm{NMR}\left(100 \mathrm{MHz}, \mathrm{CDCl}_{3}\right)$, Table 1; HR-MS at $m / z 656.2480[\mathrm{M}]^{+}$(calcd for $\mathrm{C}_{34} \mathrm{H}_{40} \mathrm{O}_{13}, 656.2469$ ).

Cytotoxicity of 1 was determined in vitro by the MTS method. Antimicrobial assays for $\mathbf{1}$ were performed in 96-well sterilized microplates using a microdilution method. The cytotoxicity of the misamycin (1) was tested by using human promyelocytic leukemia HL-60, human hepatoma SMMC-7721, non-small cell lung cancer A-549, breast cancer MCF-7 and human colorectal carcinoma SW4801 cell lines, it showed modest cytotoxicity against above tumor cells, generating $\mathrm{IC}_{50}$ values of $15.37,16.34,25.98,20.71,9.75 \mu \mathrm{M}$ against HL-60, SMMC-7721, MCF-7, A-549, SW4801 cells, respectively. Cisplatin was used as a positive control, generating $\mathrm{IC}_{50}$ values of $1.18,4.29,5.25,12.28$ and $13.85 \mu \mathrm{M}$ against HL-60, SMMC-7721, A-549, MCF-7, SW4801 cells, respectively.

In addition, misamycin (1) exhibited modest antibacterial activity against Gram- positive bacterium Staphylococcus aureus with an MIC 


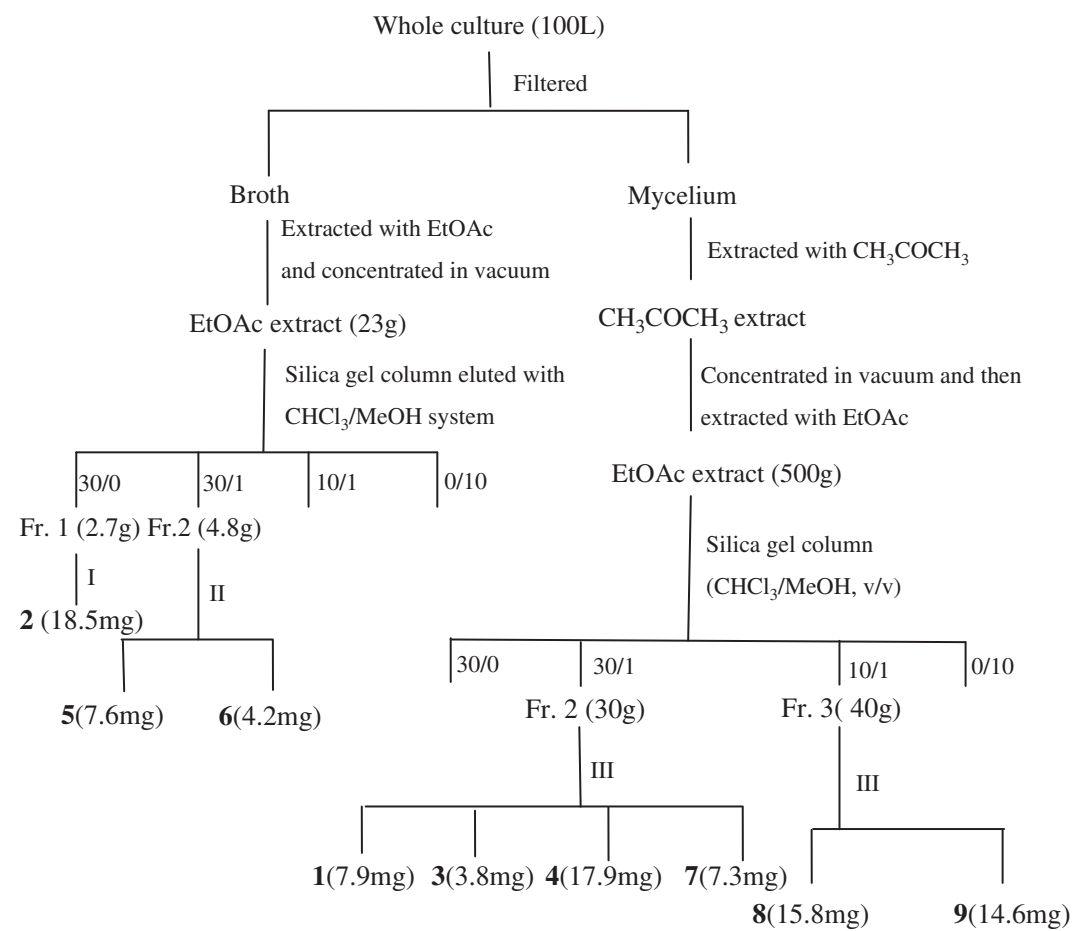

Scheme 1 Extraction of compounds 1-9 produced by Streptomyces sp. YIM66403. I: Recrystallized in $\mathrm{CHCl}_{3}$. II: Silica gel column eluted repeatedly with a $\mathrm{CHCl}_{3} / \mathrm{MeOH}$ gradient from $\mathrm{CHCl}_{3}$ to $\mathrm{MeOH}$ and Sephadex $\mathrm{LH}-2 \mathrm{O}$ (GE Healthcare Co., Buckinghamshire, UK) (MeOH). III: Silica gel column eluted with petroleum ether/ethyl acetate $(10: 1,3: 1,1: 1)$ followed by ethyl acetate and then $\mathrm{MeOH}$, a $\mathrm{CHCl}_{3} / \mathrm{MeOH}$ gradient from $\mathrm{CHCl}_{3}$ to $\mathrm{MeOH}$ and $\mathrm{Sephadex} \mathrm{LH}-20(\mathrm{MeOH})$.

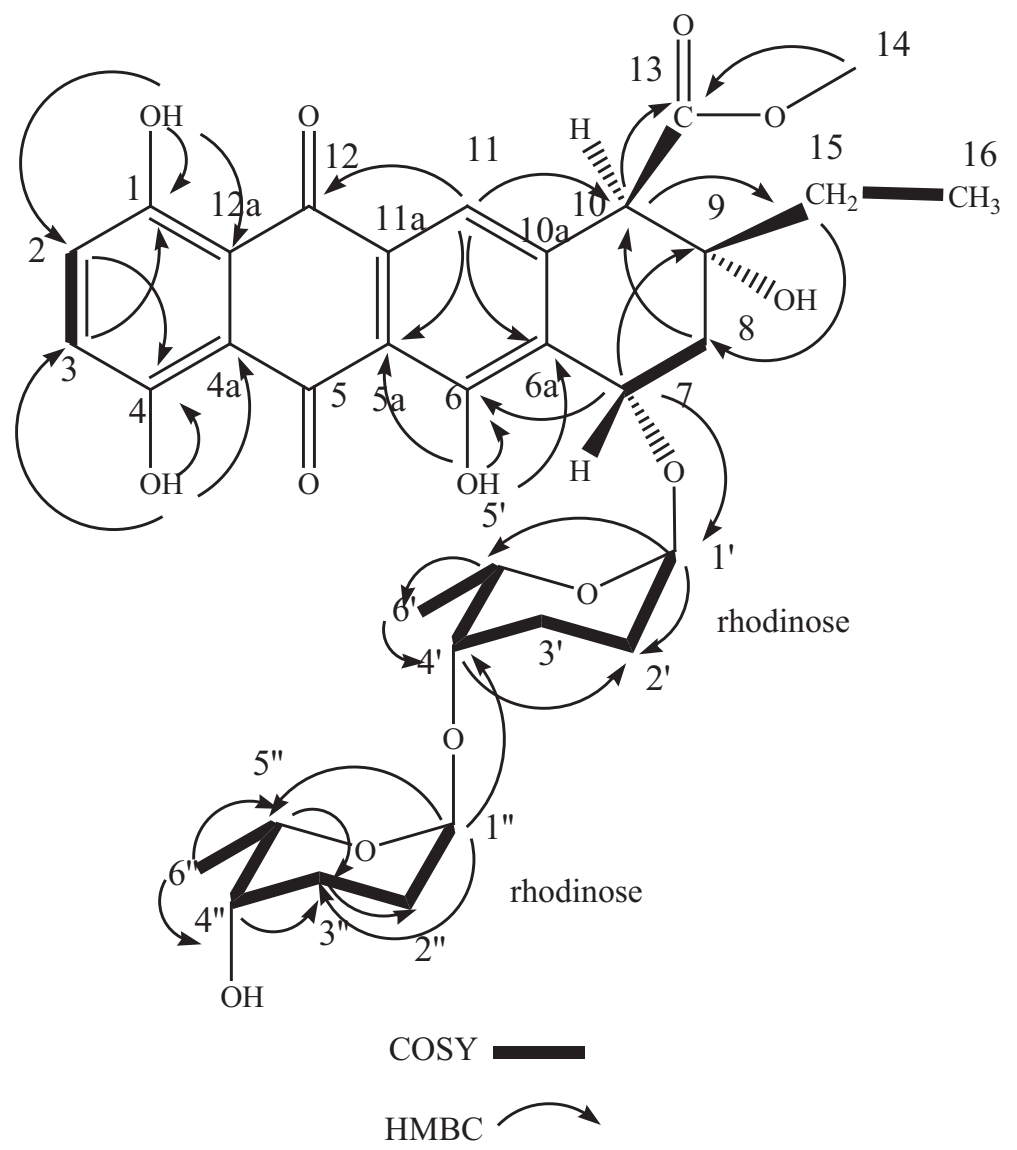

Figure 2 Key $\mathrm{HMBC}$ and ${ }^{1} \mathrm{H}-{ }^{1} \mathrm{H}$ COSY correlations for the new anthracycline 1. 
Table $1{ }^{1} \mathrm{H}(400 \mathrm{MHz})$ and ${ }^{13} \mathrm{C}$ NMR $\left(100 \mathrm{MHz}\right.$ ) spectroscopic data for 1 (in $\mathrm{CDCl}_{3}, J$ in $\mathrm{Hz}$ )

\begin{tabular}{|c|c|c|c|c|c|}
\hline Position & $\delta_{H}$ (mult) & $\delta_{C}$ & position & $\delta_{H}$ (mult) & $\delta_{C}$ \\
\hline $1-\mathrm{OH}$ & $12.91(\mathrm{~s})$ & & $12 a$ & & 112.5 \\
\hline 3 & $7.25(\mathrm{~s})$ & 130.0 & 14 & $3.69(\mathrm{~s})$ & 52.5 \\
\hline 4 & & 157.8 & 15 & $1.77,1.50(\mathrm{~m})$ & 32.2 \\
\hline $4-\mathrm{OH}$ & $12.18(\mathrm{~s})$ & & 16 & $1.02(t, 7.2)$ & 6.7 \\
\hline $5 a$ & & 114.8 & $3^{\prime}$ & $1.51,2.02(\mathrm{~m})$ & 24.5 \\
\hline 6 & & 162.3 & $4^{\prime}$ & $3.48(\mathrm{~m})$ & 74.5 \\
\hline $6-\mathrm{OH}$ & $12.74(\mathrm{~s})$ & & $5^{\prime}$ & $4.05(\mathrm{~m})$ & 67.5 \\
\hline $6 a$ & & 131.6 & $6^{\prime}$ & $1.20(\mathrm{~d}, 6.9)$ & 17.1 \\
\hline 7 & $5.27(\mathrm{~d}, 2.4)$ & 70.6 & $1^{\prime \prime}$ & $4.82(\mathrm{~d}, 3.4)$ & 99.6 \\
\hline 8 & $2.45,2.30(\mathrm{~m})$ & 33.7 & $2^{\prime \prime}$ & $1.63(\mathrm{~m})$ & 23.6 \\
\hline $11 a$ & & 132.7 & & & \\
\hline
\end{tabular}

of $64 \mu \mathrm{g} \mathrm{ml} \mathrm{m}^{-1}$, but it didn't show antimicrobial activity against fungus Monilia albican and Gram-negative bacterium Escherichia coli with MICs $>512 \mu \mathrm{g} \mathrm{ml}^{-1}$. Kanamycin showed antibacterial activity against S. aureus with an MIC of $4 \mu \mathrm{g} \mathrm{ml}^{-1}$ as a positive control.

\section{ACKNOWLEDGEMENTS}

This study was supported by the National Natural Science Foundation of China (No. 81360480).

1 Vaněk Z., Tax J., Komersová I., Sedmera P. \& Vokoun J. Anthracyclines. Folia Microbiol. 22, 139-159 (1977)

2 Fucikova J. et al. Human tumor cells killed by anthracyclines induce a tumor-specific immune response. Cancer Res. 71, 4821-4833 (2011).

3 Perego, P. et al. Role of apoptosis and apoptosis-related genes in cellular response and antitumor efficacy of anthracyclines. Curr. Med. Chem. 8, 31-37 (2001).
4 Nachtigall J., Schulz D., Beil W., Süssmuth R. D. \& Fiedler H. P. Aranciamycin anhydride, a new anthracycline-type antibiotic isolated from Streptomyces $s p$. Tü 6384*. J. Antibiot. 63, 397-399 (2010).

5 Horii Z., Momose T. \& Tamura Y. Synthetic studies on $\eta$-Pyrromycinone. V. total synthesis of $\eta$-pyrromycinone. Chem. Pharm. Bull. 13, 797-803 (1965).

6 Zhao, P. J. et al. Secondary metabolites from endophytic Streptomyces sp. Lz531. Chem. Biodivers. 4, 899-904 (2007).

7 Nakata M., Saito M., Inouye Y. \& Nakamura S. A new anthracycline antibiotic, cinerubin R taxonomy, structural elucidation and biological activity. J. Antibiot. 45, 1599-1608 (1992).

8 Zhu B. Q., Zhang Y. W., Zhang C. N. \& Tong C. Studies on new anthracycline antibioticts 80334 B, C and F II. fermentation, isolation, physicochemical properties, biological characteristics and structural determination. Yao Xue Xue Bao 21, 422-433 (1986).

9 Nakagawa, M. et al. The Structure of a new anthracycline, cinerubin $X$ produced by a blocked mutant of Streptomyces violaceochromogenes. J. Antibiot. 39, 1178-1179 (1986).

10 Nettleton, D. E. et al. Antitumor agents from bohemic acid complex, III. the isolation of marcellomycin, musettamycin, rudolphomycin, mimimycin, collinemycin, alcindoromycin, and bohemamine. J. Nat. Prod. 43, 242-258 (1980).

11 Balk-Bindseil, W. Neue Naturstoffe aus dem Screening mariner Actinomyceten. Isolierung und Strukturaufklärung der Lagumycine und des Oceamycins. PhD thesis, University of Göttingen (1995). 